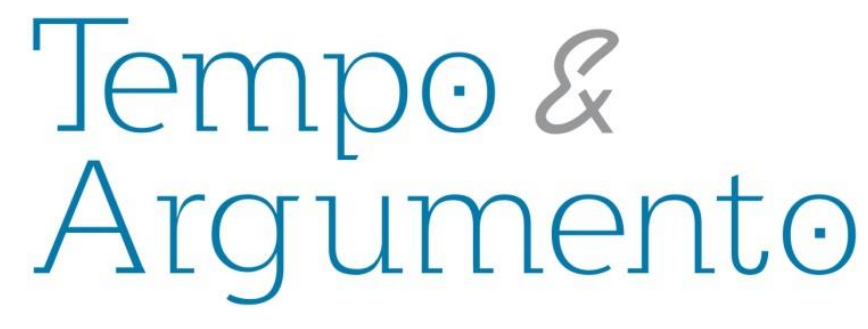

\title{
Múltiplos olhares sobre história única
}

\section{Resumo}

O artigo traça um diálogo entre autores que escrevem sobre questões relativas à história da África e à reprodução de uma leitura que reafirma estereótipos. Partimos da afirmação de Chimamanda Adichie sobre a história única para dialogar com diferentes tipos de produção escrita e observar em que medida elas se enquadram nessa perspectiva. Num segundo momento, analisamos a constituição de livros de Elikia M'Bokolo e Alberto da Costa e Silva com objetivo de investigar como autores de origens distintas, mas com grande circulação no Brasil, tratam a história da África. Concluímos demonstrando em que medida os diferentes discursos produzidos contribuem para a formação de uma história e um olhar único a respeito da África.

Palavras-chave: História da África. Historiografia.

Africanos.
Ana Mónica Henriques Lopes

Doutora em História pela Universidade Federal de Minas Gerais (UFMG). Professora da Universidade Federal de Ouro Preto (UFOP). Ouro Preto - MG - Brasil amhlopes@gmail.com

\section{Para citar este artigo:}

LOPES, Ana Mónica Henriques. Múltiplos olhares sobre história única. Tempo e Argumento, Florianópolis, v. 10, n. 25, p. 385 - 409, jul./set. 2018. 


\title{
Multiple views of an only history
}

\begin{abstract}
The article propose a dialogue between authors who write about questions relating to African history and reproduction of a reading that reaffirms stereotypes. We start with Chimamanda Adichie's assertion about the unique history to engage with different types of production written and observe to what extent they approach this perspective. In a second we analyzed the constitution of books Elikia M'Bokolo and Alberto da Costa e Silva for to investigate how this authors from different origins, but with wide circulation in Brazil, treat the history of Africa. We conclude demonstrating the extent to which different discourses produced contribute to the formation of a history and a unique perspective about Africa.
\end{abstract}

Keywords: African History. Historiography. Africans.

O passado foi mal embalado e chega-nos deformado, carregado de mitos e preconceitos. O presente vem vestido de roupa emprestada. E o futuro foi encomendado por interesses que nos são alheios.

Mia Couto

A afirmativa do biólogo e escritor moçambicano, Mia Couto (2003), alerta para a leitura de processos históricos que sem uma perspectiva local, ou endógena ${ }^{1}$ como afirma Carlos Lopes (1995), é estranha aos moçambicanos. Em “Meu nome é África”, o escritor questiona algumas visões sobre a África que resultaram num acúmulo de estereótipos que pouco explicam, reconstroem ou elucidam a realidade africana. Trata-se, em alguns casos, de reconstruções do passado que oscilam entre o encantamento e a depreciação. Revelam, algumas vezes, a África doce, encantadora, materna e ingênua; em outros, a doentia, faminta e cruel. Entre essas duas imagens, em geral reproduzidas pela mídia, uma terceira discursividade emerge dotada de credibilidade pelo discurso científico que professa.

\footnotetext{
${ }^{1}$ A questão sobre uma história endógena ou uma perspectiva africana permeia os debates sobre a elaboração da História Geral da África (UNESCO) e foi estudada em profundidade. BARBOSA, Muryatan Santana. A África por ela mesma: a perspectiva africana na História Geral da África (UNESCO) 2012.
} 
No entanto, esquecemo-nos de que informações equivocadas ou fantasiosas nem sempre partiram de ficções. Pelo contrário, um olhar mais atento nos leva a avaliar que boa parte delas são nutridas por análises que, partindo de um sistema de referenciais próprios, produziu evidências que levaram à elaboração de leituras que destoaram da realidade que pretendiam atingir, ou, talvez tenham construído uma para si².

Essa África imageticamente localizada num oriente, pasteurizada e produzida sob a ótica europeia, "representa esse papel, cultural e até mesmo ideologicamente, como um modo de discurso com o apoio de instituições, vocabulário, erudição, imagística, doutrina e até burocracias e estilos coloniais" (SAID, 2001, p. 14).

O passado "mal embalado" é fruto desse presente conectado a um outro, ao dono da veste que projeta, aspira, ou elabora expectativas a partir de experiências próprias. A história da África seria, então, elaborada a partir do outro e para o outro. Essa perspectiva pode ser um indício que nos leva a entender por que ao buscarmos diferentes bibliografias, com perspectivas e vozes autorais distintas, muitas vezes caímos em uma história única. As lacunas continuam sendo lacunas, algumas afirmações já se tornaram verdades universais incontestes e a organização textual obedece sempre um tempo homogêneo e vazio, em que os fatos são encadeados a partir de espaços de autoridades escolhidos num padrão europeu, ou em uma contraposição referenciada na Europa.

Segundo Carlos Lopes (1995), em seu texto A pirâmide invertida, a História da África viveu um período sob o peso da afirmativa hegeliana do "não tem história". Num segundo momento, ao qual o autor denominou pirâmide invertida, observamos a elaboração de trabalhos em contraposição à história europeia, que tinha nomes como Joseph Ki-Zerbo, Téophile Obenga e outros, os defensores da demonstração de que a História da África era uma antítese do que se tinha dito durante muito tempo.

O diagnóstico de Carlos Lopes (1995) é preciso quanto à publicidade que a afirmativa de Hegel alcançou entre africanistas. No entanto, mais do que

2 François Hartog, ao analisar como a construção do grego está profundamente relacionada com a do bárbaro, demonstra como o espelhamento e a alteridade são importantes na produção de um discurso histórico. Assim, “'bárbaro' no sentido de não-grego, forma, associado a 'grego', um conceito antônimo e assimétrico, acoplando um nome próprio, Héllenes, e uma designação genérica, bárbaroi" (HARTOG, 2004, p. 95). 
constrangimento, inquietação e negação, a afirmativa trouxe um problema histórico para os estudos africanos que, até onde pudemos acompanhar, não foi suficientemente pensado, a saber: qual o sentido da história, ou melhor, por que buscar e produzir um conhecimento histórico. Na afirmativa de Hegel, lê-se:

ela não faz parte da história mundial; não tem nenhum movimento ou desenvolvimento para mostrar, e o que porventura tenha acontecido nela - melhor dizendo, no norte dela - pertence ao mundo asiático europeu. Cartago foi um momento importante e passageiro; mas como colônia fenícia pertence à Ásia. O Egito será abordado como transição do espirito humano do Oriente para o Ocidente, mas ele não pertence ao espírito africano. Na verdade, o que entendemos por África é algo fechado sem história, que ainda está envolto no espírito natural, e que deve ser apresentado aqui no limiar da história universal. (HEGEL, 2008, p. 88)

Mais do que responder a afirmação sobre a ausência de "movimento ou desenvolvimento" ou a persistência do "espírito natural”, vários africanistas optaram por trabalhar a partir dos indícios arqueológicos da origem do homem e do processo de hominização e combater a tese de que o Egito pertence à história asiática. A "reafricanização" do Egito tornou-se uma das bandeiras do afrocentrismo e veio acompanhada de uma releitura da Antiguidade que aponta para as origens africanas/egípcias da Grécia ${ }^{3}$. O debate entre eurocentrismo e afrocentrismo levou à produção de trabalhos que mantiveram a estrutura antitética que de modos diferenciados, e nem sempre explícitos, influenciaram as estruturas e abordagens de pesquisas em história da África. Assim, observamos que os compêndios, coleções e obras de história geral da África sempre começam com a reafirmação da origem do homem na África, da hominização e do Egito africano que manteve mais relações com a Núbia do que recebeu influências asiáticas ${ }^{4}$.

3 Essa perspectiva pode ser lida em DIOP, C. A. Precolonial black Africa. A comparative study of the political and social systems os Europe and black Africa, from antiquity to the formation of modern states; BERNAL, M. Black Athena: The Afroasiatic Roots of Classical Civilization (The Fabrication of Ancient Greece 1785-1985); JAMES, G.G.M Stolen Legacy.

4 Entre outras, cito algumas que circulam no mercado editorial brasileiro KI-ZERBO. História geral da África, I: Metodologia e pré-história da África (2010), M'BOKOLO, E. História da África Negra. História e civilizações (2009), SILVA. A. C. enxada e a lança. LOPES, A. M. ARNAUT, L. História da África: uma introdução (2010). GIORDANI, M. C. História da África anterior aos descobrimentos (2010). PEREIRA, A. M. África para abandonar estereótipos e distorções (2010). OLIVER, R. A experiênciia africana (1994). 
Esse percurso historiográfico é compreensível na medida em que o percebemos e avaliamos como um posicionamento frente às leituras que sistematicamente procuram retratar a África à deriva da história ocidental/europeia. No entanto, como afirma Appiah (1997a, p. 51), "a final irony is that afrocentrism, which is offered in the name of black solidarity, has, by and large, entirely ignored the work of African scholars other than Diop". Essa trajetória provoca alguns vazios teóricos devido à manutenção de uma única abordagem. Consequentemente, alguns temas permanecem marginais e outros são esquecidos.

A título de ilustração, ou provocação, podemos continuar no mesmo texto de Hegel e ler: "Durante os trezentos ou trezentos e cinquenta anos que os europeus têm conhecido essas terras [África subsaariana] e tomado posse de partes das mesmas, apenas em alguns pontos e durante curto período eles ultrapassaram essas montanhas, e mesmo assim não se fixaram em parte alguma" (p. 83). Esse fragmento é significativo porque não causou repercussão. O empreendimento colonial foi dotado de uma temporalidade de séculos que serviu aos interesses europeus de definição da posse dos territórios africanos, à legitimidade dos Estados/metrópoles perante seus povos e à defesa das formas de intervenção na autonomia das populações africanas e à exploração. Apesar disto, salvo algumas exceções, ainda observamos a história da África, a partir do século XVI, demarcada como colonial. O que aparentemente poderia ser lido como uma simples terminologia, acaba proporcionando leituras embaraçosas a medida que confecciona uma imagem de infantilidade e incompetência africana frente ao europeu. A pergunta básica que se coloca quando pensamos num longo período de ocupação e exercício da autoridade por parte do estrangeiro é por que não houve reação dos naturais? Ou, por que eles demoraram até ao terceiro quartel do XIX para reagir?

O fato é que desde os primeiros contatos com europeus no século XVI, verificamse agenciamentos que variaram na forma e intensidade em conformidade aos interesses locais e proporcionais às investidas europeias na soberania das populações africanas. Como a penetração foi mais lenta e tardia do que algumas perspectivas fazem crer, a reação também obedeceu a esse ritmo. 
Cheikh Anta Diop (1987), em seu livro, Precolonial black Africa instrumentalizou a categoria pré-colonial ao demonstrar a existência de uma história endógena, com movimentos e estruturas societais. Para Théophile Obenga (2013), este foi "um gesto fundador" na medida em que a história da África passou a se fazer a partir da África e não em função de elementos externos que em dado momento estiveram naquele continente. É interessante notar que a data da publicação, em 1960, é também a de independência do Senegal - país de nascimento de Diop - e de outros 16 Estados $^{5}$.

Apesar da importância dessa obra, deve-se assinalar a denegação contida tanto no título do livro como em seu texto. A lógica de que "a África também tem história” está presente por uma insuficiente datação própria ao continente presente no referente colonial que marca o escopo temporal. O que demarca o movimento próprio de autorreferencialidade também revela a dificuldade em pensar fora do padrão modular europeu e o pré-colonial dialógica cronologicamente com Hegel, no que se refere aos 350 anos de presença europeia na África. A estrutura dos $\operatorname{capítulos}^{6}$, mesmo que sem intenção, configurou-se como resposta à ausência de movimentos próprios, uma vez que Diop primeiro resume cada movimento da história europeia - e no primeiro capítulo da Índia - e na sequência, construiu uma comparação/equiparação ao descrever as questões próprias aos povos africanos.

Para Elika M'Bokolo é importante "deixar de concentrar estes longos séculos sob o epiteto aparente cômodo, mas inteiramente anacrônico e errado, de pré-colonial. Registra-se, com efeito, um erro de perspectiva, quando não um preconceito prenhe de implicações intelectuais, mas também políticas” (2009, p. 11).

A leitura de $M$ 'Bokolo nos encaminha para a retórica que serviu ao colonialismo e ainda é utilizada pelo imperialismo, ou nas palavras de Kwame Nkrumah (1967), ao “neocolonialismo, ultimo estágio do imperialismo". Essa leitura reafirma, segundo M'Bokolo, a distinção entre ocidentais e orientais, em que "os primeiros dominam e os

5 Em sequência cronológica a data das independências em 1960: Camarões (01/01), Togo (27/04), Senegal e Mali (20/06), Zaire, atual Republica Democrática do Congo (30/06), Madagascar e Somália (1/07), Benin (01/08), Niger (03/08), Alto Volga, atual Burkina Faso, (05/08), Costa do Marfim (07/08), Chad (11/08), República Centro-Africana (13/08), Congo (15/08) Gabão (17/08), Nigéria (01/10) e Mauritânia (20/11).

6 O capítulo 4 "Political organization in Black Africa" é nitidamente uma resposta aos valores europeus apresentados resumidamente no capítulo 3 "Formation of the modern european states". 
segundos devem ser dominados, o que costuma querer dizer que suas teorias devem ser ocupadas, seus assuntos internos rigidamente controlados, seu sangue e seu tesouro posto à disposição de uma outra potência ocidental” (SAID, 2001, p. 46). A persistência dessa leitura reforça a ideia de que o continente africano é incapaz de andar sozinho. Não se trata apenas de um desvio histórico, mas de posicionamentos políticos que pela força de sua discursividade tem alimentado uma imagem de África decalcada da realidade e dependente.

Alimenta-se uma história única e a marginalização das perspectivas locais. Como afirma Said, “num nível muito básico, o imperialismo significa pensar, colonizar, controlar terras que não são nossas, que estão distante", assim como foi posto na afirmação de que

\begin{abstract}
"Moçambique é um Mato Grosso no meio da África, com terra de graça, sem tanto impedimento ambiental e frete muito mais barato para a China", diz Carlos Ernesto Augustin, presidente da Associação MatoGrossense dos Produtores de Algodão (Ampa). "Hoje, além de a terra ser caríssima em Mato Grosso, é impossível obter licença de desmate e limpeza de área." Augustin organizou a missão de agricultores para ir ao país em setembro ver as terras. Um consultor da Ampa já está no país contatando autoridades e preparando a viagem. "Quem vai tomar conta da África? Chinês, europeu ou americano? O brasileiro, que tem conhecimento do cerrado"7, diz Augustin. (FOLHA DE S. PAULO, 14.08.2011)
\end{abstract}

Essa "recolonização" de Moçambique e do Kenya - onde ocorre um processo semelhante - é resultante das escolhas dos próprios governos, mas não exclusivamente. Ainda persiste uma lógica na relação nós (africanos)/ outro (europeu) que propicia a manutenção de estereótipos e modelos de consumo que mantêm a "máscara branca" Segundo Achille Mbembe (2001) "o curso da vida é associado a um jogo de acaso (uma loteria) na qual o horizonte existencial temporal é colonizado pelo presente imediato e por cálculos prosaicos de curto prazo" que produzem uma mimetização.

Mia Couto (2003) afirma que, ao levar seus alunos para trabalho de campo, observou que "não sabiam as línguas, desconheciam os códigos culturais, sentiam-se deslocados e com saudades de Maputo. Alguns sofriam dos mesmos fantasmas dos

8 Referência à obra de Franz Fanon (2008) "Pele Negra Mascaras Brancas". 
exploradores coloniais: as feras, as cobras, os monstros invisíveis". Em seu texto "Meu nome é África", nos deparamos com uma crítica severa à forma como se olha para elementos africanos e a forma como são pensados os problemas africanos - tanto em referência ao passado como ao presente.

A mesma questão é colocada em 2009 pela escritora nigeriana Chimamanda Adichie na palestra "O perigo de uma história única”. Seu texto crítico e bem humorado remete para o fato de "que nós somos impressionáveis e vulneráveis em face de uma história, principalmente quando somos crianças". Nas histórias e estórias que lia, as referências construídas remetiam a uma imagem romântica europeia, pois os autores não eram africanos, assim como os personagens e espaços. A leitura de mundo construída desde a infância desmoronou quando se deparou com uma outra realidade encantadora, ao visitar, na aldeia de Fide, um menino pobre que morava com a família da autora. Em suas palavras:

fomos visitar a sua aldeia e sua mãe nos mostrou um cesto com um padrão lindo, feito de ráfia seca por seu irmão. Eu fiquei atônita! Nunca havia pensado que alguém em sua família pudesse realmente criar alguma coisa. Tudo que eu tinha ouvido sobre eles era como eram pobres, assim havia se tornado impossível pra mim vê-los como alguma coisa além de pobres. Sua pobreza era minha história única sobre eles.

Adichie, assim como os alunos de Mia Couto, sofreu na infância com os fantasmas produzidos pela história única 9 . No entanto, a experiência proporcionada pela imersão no "universo africano" parece ter levado a autora a observar uma distinção entre o olhar africano e o não africano. Como se o primeiro fosse detentor de uma experiência que o impele a perceber os processos inerentes ao continente de forma diferenciada em relação aos demais. No entanto, a própria identidade africana é construída na relação com o outro fora do continente e o princípio da africanidade surge dessa distinção, como a valorização de uma vivência singular e local transformada metonimicamente em global/africana.

9 O texto History and Africa /Africa and History (1999), de Joseph C. Miller, ilustra bem o tipo de educação e material didático que circulava nas ex-colônias africanas ao citar que os estudantes de países colonizados pela França tinham em seus textos a referência aos antepassados gauleses independente da origem. 
A própria palavra "africanos" remete a uma derivação de Afrig que, a princípio, era usada pelos romanos para nomear uma parte da região de Cartago e por fim nomeou a região (KI-ZERBO, 2010, p. XXXI). É importante verificarmos que essa identificação generalizante construída pelo outro, estrangeiro, se tornou numa forma de identificação individual produzindo novas subjetividades e perspectivas na relação com o outro. Em outras palavras, o indivíduo nascido na África se identifica como africano perante o outro que não nasceu naquele continente e desconhece seu local de origem, país ou região. Isso ocorre até mesmo dentro da África quando se trata de um diálogo onde há suspeita de não reconhecimento da identidade requerida.

Apropriação e reafirmação desse componente identitário geográfico como posicionamento político levou ao desenvolvimento da africanidade. Uma identidade que abriga negros de diferentes lugares do mundo que se identificam pela ancestralidade estabelecida através do conceito de raça fomentado a partir de uma matriz cultural euroamericana (ANDRADE, 1997, p. 161). Essa construção que remonta o século XIX disseminou-se com maior ímpeto a partir da década de 1920 com o pan-africanismo e parece ter sido essencial para a construção dos nacionalismos africanos que alimentaram os movimentos de libertação após a Segunda Guerra Mundial. Segundo Assante, o panafricanismo é um "movimento político e cultural que considera a África, os africanos e os descendentes de africanos de além-fronteiras como um único conjunto, e cujo objetivo consiste em regenerar e unificar a África, assim como incentivar um sentimento de solidariedade entre as populações do mundo africano" (2010, p. 874) ${ }^{10}$.

Observamos que o princípio unificador é utilizado como mecanismo de valorização e constituição de uma discursividade em prol de uma autonomia intelectual e política. No entanto, ao operar com os mesmo elementos colocados pelo lluminismo para distinção entre africanos e humanos reafirmou o princípio ontológico que serviu de base para

\footnotetext{
10 A proposta pan-africanista enquanto forma de identificação e luta surge nos EUA e tem entre seus maiores expoentes William Edward Burghardt Du Bois ou Henry Sylvester Williams. Durante a segunda metade do século XX, ganhou novo ímpeto devido às independências dos Estados africanos e como contraposição ao pan-arabismo que se expandiu pelos países mediterrâneos africanos depois da eleição de Gamal Abdel Nasser e da progressiva filiação à Liga Árabe por parte da Líbia (1953), Sudão (1956), Marrocos (1958), Tunísia (1958), Argélia (1968), Mauritânia (1973), Somália (1974), Djibouti (1977) e Eritreia (2003).
} 

africanos.

Em termos historiográficos, esse posicionamento impede a leitura das singularidades dos povos africanos. Se os povos africanos tiveram o seu legado roubado, sua autonomia limitada e seus processos de subjetivação mutilados, como podem ser “protagonistas" de sua história? Por que ainda estudamos a história da Europa na África e não a história da África? Produz-se sob uma aparente história dupla - que a rigor seria excludente - a acusação ao outro justificada pelas condições atuais da África; mas essa mesma acusação serve de elemento catalizador para demarcar a distinção e provar a superioridade africana.

Ao final, parece estarmos diante do encontro dos livros Orientalismo. O oriente como invenção do ocidente, de Edward Said, e Ocientalismo. O ocidente aos olhos de seus inimigos, de lan Buruma e Avishai Margalit, que a partir do "ocidente" buscam o perfil do oriente. O primeiro, com grande erudição, demonstra ou pelo menos desvela os caminhos percorridos pela construção moderna do "oriente". O segundo livro, na tentativa de retratar o olhar do oriente demonstra como o ocidentalismo nasceu na Europa, antes de se transferir para outras partes do mundo (BURUMA e MARGALIT, 2006, p. 12). Nessa obra, ocidente e modernidade se confundem e os críticos ou inimigos do ocidente, assim como seus desejantes, miram os ícones da modernidade, como, por exemplo, a metrópole. Parece que, mais uma vez, estamos diante de um movimento de rotação: andamos, andamos e caímos no mesmo, porque não mudamos o eixo da reflexão: ainda mantemos como padrão a ser alcançado o “modelo ocidental”.

Se pensarmos que as organizações políticas na África e seus lideres não reagiram da mesma forma à presença do europeu, variando numa escala complexa entre a negação imediata e o estabelecimento de acordos duradouros, nos depararemos com múltiplas historicidades que rompem com o princípio homogeneizante da ocupação e colonização. Esses processos tiveram temporalidades diferentes que operaram com características regionais que incluem a possibilidade e viabilidade das resistências e os 
interesses econômicos e políticos envolvidos. Assim, é no mínimo imprudente traçarmos um quadro linear e fechado para a totalidade do continente.

Na história única do continente, escrita por africanos e não africanos, elementos dissonantes da organicidade muitas vezes são marginalizados. Neste quadro, encontramos africanos como Honória Bailor-Caulker ${ }^{11}$, que em seu discurso na American Anthropological Association, em 1977, causou constrangimento ao admitir publicamente que era descendente de traficantes de escravos. Seu posicionamento revelava uma outra história que percorre o caminho inverso da unidade proposta por Alexander Crummell, Eduard W. Blayden, W. E. B. Du Bois ${ }^{12}$ e outros pan-africanistas, pois evidencia que o princípio racial que unia africanos e afrodescendentes não esteve presente em todos os percursos históricos. Esse esquivamento é perceptível também na persistência em anular a africanidade do "bôer" ou "africâner". A grande ironia desse processo está na manutenção de um discurso de negação identitária produzido na segunda metade do século XIX, quando foi necessário limitar os conflitos na África do Sul e estabelecer a autoridade inglesa ${ }^{13}$, pois todos se encontravam sob suspeita: africâneres (bôers), whites, coloureds, indigenous, natives ou blacks não tinham direito a identidades territorializadas, eram apenas habitantes.

No diagnóstico de Mia Couto, "o modo maniqueísta e simplificador com que se redigiu o chamado "tempo que passou" teve, porém, outra conseqüência: fez persistir a ideia de que a responsabilidade única e exclusiva da criação da escravatura e do colonialismo cabe aos europeus" (2003).

11 Honória Bailor-Caulker era chefe da cidade de Shenge, no distrito Moyamba, em Serra Leoa. Além da referência ao episódio no texto de Mia Couto, Meu nome é África, o episódio é citado com transcrição parcial de seu discurso no livro de William E. Phipps, Amazing Grece in John Newton: slave ship captein, hymn writer, and abolitionist.

12 A obra de Du Bois desvia-se do roteiro inicial do pan-africanismo e, em certa medida, de muitos autores afrocentristas ao elaborar a teoria da dupla consciência que leva a identidade negra a dividir-se entre o apelo da raça e a ancestralidade africana e a universalidade da modernidade (GILROY, 2001).

13 Poucos textos consultados apresentam a palavra africanos/afrikaans para a população da África do Sul até o final da primeira década do século XX. O mais próximo que encontramos foi indigenous e native, mas ambos usados para a população negra. Observamos as seguintes identificações para os habitantes: briton, european, farmer, boer, white, black, bantu, zulus, xhosas, coloured. Kaffirs e caffres. Essas referências podem ser vistas, entre outros, em Act 1909, de Union South Africa; Convention for the Settlement of the Transvaal Territory, 1881; Boers and Bantu, de George McCall Theal; Briton and Boer. Maurice S. Evans; The Union os South Africa, de R. H. Brand. 
Isso nos leva a pensar na crítica de Partha Charteejee às formas modulares usadas para analisar os nacionalismos e as questões relacionadas à construção do Estadonacional que limitam as possibilidades de leitura:

A Europa e a América, os únicos verdadeiros sujeitos da história, elaboraram, em nosso benefício, não apenas o roteiro do esclarecimento e da exploração coloniais, mas também o de nossa resistência anticolonial e da nossa miséria pós-colonial. (BALAKRISHNAN, 2000, p. 229)

As formas modulares e outros roteiros predefinidos produzem obstáculos teóricos e metodológicos à produção de modelos de análise e construção historiográfica fora dos parâmetros euro-estadunidenses. Na base dessa produção, observamos

que a relação dos escritores africanos com o passado africano é uma trama de ambiguidades delicadas. Se eles aprenderam a não o desprezar nem tentar ignorá-lo - e há muitas testemunhas das dificuldades dessa descolonização da mente -, ainda estão por aprender a assimilá-lo e transcendê-lo. (APPIAH, 1997, p. 115)

O lugar social do historiador demarca limites e conexões historiográficas que, por sua vez, produzem um percurso escritural alçado ao lugar do conhecimento. Por essa via, uma unidade discursiva se torna a única verdade, a única história. A ruptura com esse padrão advém, em parte, do despir "as máscaras" e produzir um universalismo em que "the name Black depends not on repetition but on the radical difference without which the dis-encosure of the world is impossible" (MBEMBE, 2001, p. 160).

Sem tal ruptura, o pensamento africano se mantém enclausurado às formas modulares que associadas à necessidade de releitura ou investigação do passado corroboraram para a manutenção da visão homogeneizante e demarcadora de limites na relação nós/outro nos textos dos próprios afrocentristas e/ou pan-africanistas ${ }^{14}$. A maior dificuldade, no entanto, talvez seja definir de maneira menos racial e abstrata o que é ser africano. Para Mia Couto,

14 Apesar de muitos intelectuais compartilharem tanto da perspectiva afrocentrista quanto da panafricanista, são reflexões distintas, em que, por parte do afrocentrista, necessariamente, não se verifica uma identidade racial-africana. 
“Dado de essência”, “exotismo”, "unidade racial' e outras expressões servem para diagnosticar que existe e persiste uma organicidade discursiva que produz uma igualdade/distinção que nivela e homogeneíza as populações africanas e suas historicidades. Neste ponto, afrocentristas e eurocentristas ${ }^{15}$ vêm construindo uma história única pautada em referenciais exógenos ou construídos numa suspensão temporal que nivela experiências com o tempo, o espaço e a produção de subjetividades (WAMBA-DIA-WAMBA, 1992).

Essa essência produzida pela historiografia levou um professor estadunidense a afirmar para Adichie que seu romance não era "autenticamente africano". Nas palavras da autora:

Bem, eu estava completamente disposta a afirmar que havia uma série de coisas erradas com o romance, que ele havia falhado em vários lugares. Mas eu nunca teria imaginado que ele havia falhado em alcançar alguma coisa chamada autenticidade africana. Na verdade, eu não sabia o que era "autenticidade africana".

A esses dois estereótipos poderíamos dotar, supostamente, dois olhares distintos sobre as historicidades africanas. O olhar africano possibilitaria a produção de escritas históricas diferenciadas uma vez que a construção argumentativa, a escolha de abordagens, temas e fontes, as explicações e as formações conceituais seriam forjadas na experiência africana. No entanto, nem sempre é possível observar essa distinção e o que poderia ser uma história múltipla ou diversa acaba sendo um pouco mais do mesmo que contribui para a consolidação da história única. Como afirma Adiche, A “única história cria estereótipos". E o problema com estereótipos não é que eles sejam mentira, mas que eles sejam incompletos. Eles fazem um história tornar-se a única história.

15 Achille Mbembe, em As formas africanas de auto-incrição, avalia que a construção da identidade africana por narrativas históricas e discursos políticos está relacionada a uma perspectiva nativista que procura na origem a solidariedade, e sua instrumentalização é marcada por um economicismo marxista que fomentou a formação dos discursos nacionalistas. 
Achille Mbembe (2001) aponta como temas importantes da retórica panafricanista o colonialismo, a escravidão, o apartheid e a origem da humanidade que leva a reafirmações como "somos seres humanos como quaisquer outros. Ou: temos um passado glorioso que testemunha nossa humanidade". Nestes temas, os processos de denegação e fuga sustentam a equidade, a valoração e vitimização do africano. Assim, em sua dupla construção, processa-se uma absolvição pelos infortúnios e, ao mesmo tempo, pela ancestralidade, tradição e historicidade verifica-se a reabilitação do ser africano através da quebra do estereótipo da bestialidade e infantilidade. Entretanto, o problema desse tipo de construção discursiva são as lacunas deixadas, as perguntas não respondidas e os silêncios produzidos.

Como ilustração do que procuramos discutir neste texto, recorremos a duas referências importantes para o estudo de história da África no Brasil que nos possibilitam observar a permanência de uma história única construída pela fuga e denegação: História da África Negra, tomo I, de Elikia M'bokolo e A enxada e a lança, de Alberto Costa e Silva. Como elementos de reflexão, abordaremos a construção da temporalidade e do espaço como referenciais constitutivos da unidade da obra que têm como referente a organização política da historiografia europeia do século XIX.

Neste sentido, apesar de M'Bokolo trazer para seu texto datações pautadas na estrutura histórica egípcia ou árabe juntamente à cristã - $x$ anos a.C. ou d.C. - não modifica muito a estrutura narrativa. Pelo contrário, como podemos observar no fragmento abaixo, surge uma miscelânea de datas que obrigam o leitor a criar uma tábua numérica para acompanhar a narrativa:

A força do rei parece assegurada pelo fato de, nos princípios do século XVI a.C., um mensageiro do rei dos hicsos, Apofis, ter solicitado ao "príncipe de Kush" ajuda militar contra o rei egípcio. O restabelecimento da autoridade dos faraós levada a cabo pela XVII dinastia e mais particularmente por Tutmés I (-1530/-1520) teve como efeito a submissão de Kush ao Egito. (M'BOKOLO, 2009, p. 79)

O texto acima é incompreensível ao leitor desavisado. A falta de padronização é um vestígio do desvio em relação às abordagens tradicionais que usam o Ano Domini antes ou depois de Cristo) como sistema de organização e definição cronológica. 
Pensando na cronologia como um elemento organizador da narrativa, observamos que o subtítulo da obra é significativo: “Tomo I - até o século XVIII". Primeiro porque foge à demarcação colonial não-colonial do século XVI como determinante na alteração dos processos africanos. Segundo porque sugere uma história sem começo e sem fim, na medida em que o Tomo II apresenta como subtítulo: “do século XIX até aos nossos dias”' ${ }^{\prime 6}$ Sua proposta é uma história endógena, que opera com uma leitura da África a partir da África. Assim, em sua introdução, como citado anteriormente, questiona a ideia de demarcação temporal a partir do pré-colonial que, segundo o autor, reporta a leituras equivocadas e preconceituosas. Sua abordagem traça um diálogo teórico com Fernand Braudel e reflete sobre a longa duração e a economia-mundo. Este último parâmetro parece ser um dos elementos que define o final do Tomo I ao refletir sobre o intervalo de tempo entre os séculos XV e XVIII como "um período intermediário de duas eras dominadas pelos grandes impérios de vocação comercial, religiosa e política" (p. 517). Observamos que a abordagem teórico-metodológica dos temas africanos é muito influenciada pela obra "Civilização Material, economia e capitalismo. Século XV ao XVIII", de Braudel ${ }^{17}$, cujas marcas estão presentes especialmente em dois momentos: 1 . No capítulo "VI. As dinâmicas de longa duração - Séculos XV-XVII" em que percebemos a leitura dos processos históricos relacionando a abordagem econômica a fatores culturais e políticos em que "estruturas do cotidiano" interferem numa dinâmica maior; 2. A composição das partes do livro que a partir da terceira, “III- Os Tráficos negreiros Séculos VII-XIX", compõem um mapeamento de economias-mundo. Por essa abordagem, o autor procura construir uma leitura endógena que tenta escapar dos rótulos do período colonial, pós-colonial e estudos pós-coloniais.

Esse posicionamento demarca um questionamento à leitura recorrente de que o colonialismo na África é datado do século XVI e reforça os processos inerentes à África e aos agenciamentos coletivos entre os africanos e entre estes e os não africanos.

A estrutura de sua obra apresenta capítulos temáticos ordenados linearmente dentro de uma cronologia que se inicia com o debate da "anterioridade da África" e a

16 Não é nosso interesse e nem caberia no escopo do artigo pensar o Tomo II, apenas achamos interessante sinalizar a ausência de fixidez cronológica.

17 Apesar de ser citado na página 589, não consta das referências bibliográficas. 
estudo, que por sua vez torna a África um apêndice do Mediterrâneo e do Índico, em especial no volume 2. Em um outro livro, Memórias do Mediterrâneo, as referências à África são condicionantes a percursos explicativos do Mediterrâneo e da Europa. Neste sentindo, mesmo operando com uma leitura temporal e da "economia-mundo", é inegável o descentramento feito por M'Bokolo e, consequentemente, a produção de uma perspectiva africana.

Internamente, o texto reproduz fragmentos de documentos como mecanismo de interlocução entre autor, leitor e fontes oscilando entre a história-problema e a histórianarrativa como o próprio autor afirma na introdução. No entanto, falta-lhe a apropriação e ressignificação de conceitos, o desenvolvimento teórico e o trabalho metodológico necessários à consolidação de sua proposta de uma leitura endógena.

Em relação ao tráfico de escravos, a imagem islâmica ou de um tráfico comandado por forças externas ao continente sobrepõe-se ao fato de que a penetração árabe é muito antiga e quando Maomé lançou as bases do islamismo, elementos da cultura árabe já se faziam presentes. Assim, o islâmico que traficava homens e mercadorias era, em parte, também africano.

Se por um lado, seu texto avança em vários pressupostos da construção histórica desvencilhada do também apontado por Carlos Lopes (1995), por outro, repete o padrão de historicidade não africano. Seu livro é marcado pelos temas tráfico, escravidão islâmica e europeia e a reafirmação dos primórdios da humanidade na África e da existência de

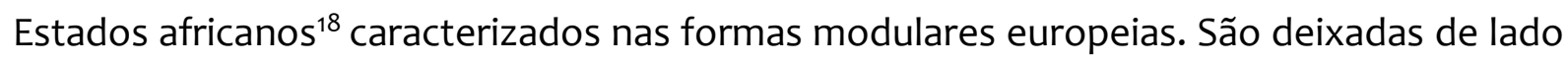
as estruturas societais africanas em favor de uma história interligada com o mundo Árabe em especial. Parece-nos que constitui-se por esse caminho uma história dos árabes e

18 Essa reafirmação como elemento de valorização africana dissociada da questão teórica e metodológica pode ser observada em fragmentos como: No plano da "política externa", os reis de Axum organizaram a partir do século I uma política contínua de expansão que iria fazer do reino uma das potências "mundiais" da era cristã. De fato foi um Estado muito importante, mas pensar em potência mundial exigiria uma reflexão sobre a extensão desse mundo e da magnitude desse potencial. Esse fragmento beira o anacronismo (p. 91). 
islâmicos na África e, depois, a dos europeus na África. Não se trata exclusivamente do problema a ser abordado, mas da forma como é trabalhado. Existe alguma diferença entre falar das estruturas mandigas a partir do século XII e seu confronto com peuls e bambaras, e a escravidão ou islamização da África, ou como M'Bokolo escreve: “A islamização: uma história a reescrever." Trata-se, nas palavras de Carlos Lopes, de perceber os fenómenos socio-políticos da Guiné-Bissau e da região em que está inserida a partir de uma historicidade endógene que minimiza a relação com o exterior".

No caso específico desses grupos e das reações frente à islamização, nos parece que outras questões podem ser observadas, como por exemplo, as rotas de comércio transaarianas, a valorização do ouro e do sal, a formação de vilas e cidades em função do surgimento de novos mercados. Os agenciamentos políticos em função da detenção ou organização dos centros comerciais é de tal forma importante no período anterior ao século XV que os impérios de Ghana, Mali e Songhay ocuparam subsequentemente a mesma região, suas capitais fortaleceram-se em parte pelo desvio de rotas e pelo crescimento de novos postos de comercialização. Relacionado aos processos econômicos, estão opções políticas - entre elas a conversão ao islã - e culturais, envolvendo diferentes etnias e as liberdades que operam com a religiosidade e a escravidão. Temos, portanto, transformações que foram impulsionadas pelo comércio transaariano no contato com mercadores árabes ou islâmicos mas definidas por locais, africanos islamizados ou não. Trata-se de processos complexos que exigem leituras que operem com uma história vista de baixo, a partir das experiências dos locais para perceber quais as linhas ligavam as estruturas de poder e como eles as percebiam (THOMPSON, 1987).

Nesse sentido, não se trata necessariamente de reinventar a história, ressemantizar conceitos, mas de pensar os processos a partir da realidade africana e da adesão de determinados procedimentos a sua realidade. Como afirma Mia Couto,

os conceitos (a que acrescento abordagens e métodos) devem ser ferramentas vitais na procura desse nosso retrato. Contudo, muito do quadro conceitual com que olhamos Moçambique assenta em chavões que, à força de serem repetidos, acabaram não produzindo sentido. Dou exemplos. Falamos muito de poder tradicional, sociedade civil, 
comunidades rurais, agricultura de subsistência. Perdoem-me a incursão abusiva nestes domínios. Mas tenho sinceras dúvidas sobre o rigor e a operacionalidade desses conceitos.

No livro A enxada e a lança. A África antes dos portugueses, o enquadramento forçado ou a perspectiva estrangeira à África citada por Mia Couto já se revela no próprio título. Um olhar mais atento para a realidade do continente nos permite afirmar que nem enxadas e nem lanças são representativas de todo período, espaço e populações abordados pela obra. Estamos diante de um título que talvez fale mais de um mercado cheio de clichês do que da própria obra que tem muitos méritos.

O livro começa pela "hominização do africano"19 que remete à necessidade de se provar que a humanidade vem da África e que, portanto, os africanos são humanos e iguais aos outros humanos. Por mais que isso pareça um pleonasmo, na realidade é isso que se deseja alcançar. Para apagar a associação dos africanos à imagem bestializada produzida durante séculos, verificamos a persistência nesse passado longínquo, dominado de incertezas e referências generalizantes. É como se o continente não produzisse nada de humano e necessitasse dessa estratégia absolvedora da imagem demoníaca. São formas de pensar a história, como diz Adichie:

Comece uma história com as flechas dos nativos americanos, e não com a chegada dos britânicos, e você tem uma história totalmente diferente. Comece a história com o fracasso do estado africano e não com a criação colonial do estado africano e você tem uma história totalmente diferente.

Neste sentido, uma coisa é escrever a pré-história africana, a outra é reafirmar a humanidade do africano e a gênese dos seres humanos; uma coisa é falar sobre a história da África, a outra é falar do mundo e da participação dos africanos na sua composição.

No subtítulo da obra de Alberto Costa e Silva, ao contrário de Elikia M'Bokolo, a presença do outro - o português - define o fim de uma trajetória ou história. A dupla leitura advinda deste título infere que houve uma mudança nas dinâmicas continentais causadas pela presença portuguesa e, ao mesmo tempo, o fim de uma história própria.

19 Elemento que também está presente na obra de M'Bokolo. O primeiro capítulo contém o tópico "A anterioridade africana" com os sub-tópicos "A África e o processo de hominização" e "A África e o gênero homo". 
Etiópia que

em 1452, os turcos tomam Constantinopla. E, no início do século XVI, assenhoram-se do Egito e das costas da Arábia e ensaiam o avanço sobre o Índico. Ali encontram, porém, a buscar o comando das águas e firmes em vários pontos da costa africana, das ilhas do Índico e do subcontinente indiano, os portugueses, que a eles se haviam antecipado. (2006, p. 632)

Esse fragmento causa certo estranhamento porque sabemos que a penetração portuguesa na costa do Índico foi muito difícil mesmo com o ato de vassalagem de Monomotapa. A insubordinação ao ato e autodeterminação daquelas populações levou à queda do império e a conflitos que só foram minimizados no início do século XX. Como exemplo, podemos citar a autodeterminação dos ngunes ${ }^{20}$ e a dificuldade em Portugal vencê-los e aprisionar o Rei Ngungunhane, em 1905 (VILHENA, 1996). Podemos pensar nesse episódio como uma deficiência portuguesa ou, vendo a história dessa população, observar desde o século XVIII como eles se impunham a grupos menores ou estrangeiros. Além disso, vários povos islamizados já circulavam pela região desde o século IX atuando nas exportações de produtos e escravos para a Índia a partir de Sofala.

No desdobramento da obra de Alberto Costa e Silva observamos na linearidade cronológica a demarcação capitular próxima à história-narrativa dos grandes acontecimentos, reinos, impérios e ocupações. Os títulos constituem uma relação direta com as organizações políticas. Apesar da longa pesquisa bibliográfica traduzida pelas referências ao final do livro, observamos um diálogo mínimo com fontes e com a própria bibliografia, fazendo com que o texto denso em informações tenha aparência de uma completude próxima ao tabuleiro de xadrez do corcunda de Walter Benjamin.

20 Os falantes de nguni reagiram imediatamente à entrada portuguesa no século XVII. Os agenciamentos decorrentes do deslocamento para o sul e, posteriormente, para Moçambique, levaram, entre outras coisas, à fundação do Lesotho e da Swaziland, à estruturação dos zulu e ao estabelecimento do Reino Gaza. 
No prefácio da $1^{\text {a }}$ edição, o autor fornece uma pista para a linearidade e falta de um diálogo com as fontes. Afirma que: "só o escrevi com o pensamento e o objetivo de entregar ao leitor um manual — simples, claro, direto, embora emotivamente interessado — que Ihe servisse como introdução ao conhecimento da África" (p. 13). O problema é que seu é texto pouco didático, o volume de informações e a própria edição do livro impedem que ele seja lido e usado como um manual .

Nesta parte, como em outras, falta clareza das opções teórico-metodológicas e justifica seu percurso intelectual pelo encantamento com as obras de Gilberto Freyre, Nina Rodrigues, Artur Ramos e Manuel Quirino que o levaram a quer saber mais sobre África para entender melhor o Brasil. Sua obra reflete o percurso de um grande estudioso e seu prefácio esclarece o motivo de tantas informações, pois não se trata de uma história-narrativa ou história-problema, mas da descrição de grandes conjuntos societais reinos, impérios, Estados - que podem elucidar as linhas que unem os dois continentes.

Nessas descrições alguns elementos podem ser vistos como pontos de partida para investigações que busquem outros caminhos. Quando lemos os capítulos dedicados a Gana e Mali, mesmo não havendo uma problematização, os elementos políticos, econômicos e culturais descritos provocam o leitor a pensar quão dinâmico era aquele espaço e o período entre os séculos X e XV. A associação das informações depositadas nestas partes permite, por exemplo, entender os conflitos e deslocamentos de grupos étnicos e, séculos depois, como esses grupos interagem frente ao tráfico Atlântico ${ }^{21}$.

Apesar dos problemas apontados nos livros de M'Bokolo e Costa e Silva é inegável a contribuição de ambos para os estudos africanos no Brasil. No entanto, é importante observarmos que ambos acabam fazendo parte de uma história única do continente. Como tentamos demonstrar a origem do olhar - Congolês ou Brasileiro - não foi determinante para a produção da história a partir dos agentes africanos. Como tentamos mostrar a questão de uma "história múltipla", que está mais relacionada às opções teóricas e metodológicas. Talvez, como afirma Mbembe, seja importante começarmos a refletir que "the name [negro] refered not to a biological reality or skin color bat to one

\footnotetext{
${ }^{21}$ Na obra do autor "A manilha e o libambo: a África e a escravidão de 1500-1700." (2002) essas histórias cruzadas se tornam mais evidentes.
} 
versão, impede o confronto de ideias e o desenvolvimento de abordagens próprias às realidades africanas. Não podemos esquecer que os grandes desdobramentos historiográficos surgiram da insatisfação com um tipo de história se em história da África não podemos ainda falar de "escolas" ou "linhas historiográficas", uma vez que a própria institucionalização da área é recente, mas podemos pensar em perspectivas e diálogos desenvolvidos nos estudos pós-coloniais e decoloniais. Em History after Apartheid (2003), Annie E. Coombes demonstra como as várias vozes sul-africanas emergiram depois de 1990 trazendo à tona diferentes modelos de conhecimento histórico e narrativas sobre o passado conflitantes. O processo debatido no livro demonstra como a "história única" do Apartheid e/ou do colonialismo constituiu uma visão parcial e insatisfatória do passado que precisou ser revisitado no momento em que novos atores adquiriram voz no contexto político da África do Sul.

Por fim, é importante salientar que o problema das produções que reafirmam de alguma maneira o que Adichie chamou de “história única” é perdermos dimensões do presente por usarmos discursos apoiados em realidades externas. Como afirma Mia Couto:

É importante fazermos nova luz sobre o passado, porque o que se passa hoje em nossos países não é mais do que a atualização de conivências antigas entre a mão de dentro e a mão de fora. Estamos revivendo um passado que nos chega tão distorcido que não somos capazes de o reconhecer. 


\section{Referências}

ADICHIE, Chimamanda. O perigo de uma única história. In: TED: Ideas worth spreading. Tradução e legendas por Erika Rodrigues. 2009 <http://www.ted.com/talks/lang/pt-br/ chimamanda_adichie_the_danger_of_a_single_story.html> Acesso em: 20 jan. 2012.

ANDRADE, M. P. de. Origens do nacionalismo africano. Lisboa: Dom Quixote, 1997.

APPIAH, Kuame Anthony. Na casa de meu pai: a África na filosofia da cultura. Rio de Janeiro: Contraponto, 1997.

ASANTE, S. K. B.; CHANAIWA, David. O pan-africanismo e a integração regional. História geral da África, VIII: África desde 1935. Brasília: UNESCO, 2010.

BARBOSA, Muryatan Santana. A África por ela mesma: a perspectiva africana na história geral da África (UNESCO). 2012. Tese (Doutorado) - Universidade do Estado de São Paulo, São Paulo, 2012. Disponível em: < http://www.teses.usp.br/teses/disponiveis/8/8138/tde09012013-165600/pt-br.php > Acesso em: 12 set. 2017.

BALAKRISHNAN, Gopal. O mapa da questão nacional. RJ: Contraponto, 2000.

BURUMA, lan, MARGALIT, Avishai.Ocidentalismo: o Ocidente aos Olhos de Seus Inimigos. Rio de Janeiro: Jorge Zahar, 2006.

BERNAL, M. Black athena: the afroasiatic roots of classical civilization (the fabrication of ancient greece 1785-1985). London: Free Association Books, 1987.

BRAUDEL, F. Civilização material, economia, e capitalismo: séculos XV ao XVIII. São Paulo: Martins Fontes, 1998.

BLYDEN, E. W. Hope for Africa: discourse. Liberia's offering: being addresses, sermons, etc. New York: J. A. Gray, 1862.

BRAND, R. H. The Union os South Africa. Oxford: At the Claredon Pres, 1909.

COOMBES, Annie E. History after apartheid: visual culture and public memory in a democratic South Africa. Durham: Duke university press, 2003.

COUTO, Mia. O meu nome é África. In: Continente multicultural, Companhia Editora de Pernambuco, Edição n. 34, Out. de 2003. Disponível em: 
<http://www.casadasafricas.org.br/tlautor/couto-mia/ >. Acesso em: 20 fev. 2012.

DIOP, C. A. Precolonial black Africa: A comparative study of the political and social systems os Europe and black Africa, from antiquity to the formation of modern states. Connecticut: Lawrwnce Hill \& Company, 1987.

EVANS, Maurice S. E. Black and white in the southern state: a study of the race problem in the United States from a South African point of view. London, Longmans, Green and Co, 1915 .

FARIAS, P. F. De Moraes. Afrocentrismo: entre uma contranarrativa histórica universalista e o realismo cultural. Afro-Ásia, Salvador, n.29/30, p. 317-343, 2003.

GILROY, P. O atlântico negro. SP: Ed.34; Rio de janeiro: Universidade Candido Mendes, Centro de Estudos Afro-Asiáticos, 2001.

HARTOG, Fançois. O espelho de Heródoto: ensaio sobre a representação do outro. Belo Horizonte: Ed. UFMG, 1999.

HEGEL, Georg Wilhelm Friedrich. Filosofia da História. Brasilia: Ed. UNB, 1999.

JAMES, G. G. M. Stolen Legacy. Greek Philosophy is Stolen Egyptian Philosophy. The Journal of Pan African Studies, 2009. Disponível em: <http://www.jpanafrican.com/ ebooks/eBook\%20Stolen\%2oLegacy.pdf>. Acesso em: 01 mar. 2013.

KI-ZERBO, Joseph (ed). História geral da África, I: metodologia e pré história da África. 2.ed. rev. Brasília : UNESCO, 2010.

LOPES, A. M. ARNAUT, L. História da África: uma introdução. Belo Horizonte: Crisálida, 2010.

LOPES, A. M. Neocolonialismo em África. Sankofa. Revista de história da África e de estudos da diáspora africana, n.08, 2011. Disponível em: <https://sites.google.com/site/revistasankofa/sankofa8/neocolonialismo-em-africa > Acesso em: 02 set. 2017.

LOPES, Carlos. A Pirâmide Invertida: historiografia africana feita por africanos. Actas do Colóquio Construção e ensino da história da África. Lisboa: Linopazes, 1995.

LOPES, Carlos. Os limites históricos de um fronteira territorial: Guiné “portuguesa” ou 
Guiné-Bissau. Lusotopie. Paris. 1994. Disponível em:

<http://www.lusotopie.sciencespobordeaux.fr/somma94.html.> Acesso em: 20 jan. 2015.

MBEMBE, Achile. As formas africanas de auto-inscrição. Estudos Afro-Asiáticos. v.23, n.1, p. 171-20, 2001, Disponível em: < http://www.scielo.br/pdf/eaa/v23n1/

a07v23n1.pdf > Acesso em: 11 set. 2017.

MBEMBE, Achile. Critique of black reason. Johannesburg: Wits Universty Press, 2017

MILLER, Joseph C. Presidential address: history and Africa/Africa and history. The American Historical Review, v. 104, n. 1, p. 1-32., feb., 1999.Disponível em: < http://www.ecu.edu/african/sersas/jmahapa.htm >. Acesso em: 20 fev 2013.

M'BOKOLO. África negra: história e civilizações. Tomo I (até o século XVIII). Salvador: EDUFBA; São Paulo: Casa das Áfricas, 2009.

M'BOKOLO. África negra: história e civilizações. Tomo II (Do século XIX aos nossos dias). Salvador: EDUFBA; São Paulo: Casa das Áfricas, 2011.

NKRUMAH, K. Neocolonialismo: ultimo estágio do imperialismo. Rio de Janeiro: Civilização Brasileira, 1967.

OBENGA, Théophile. 0 sentido da luta contra o africanismo eurocentrista. Luanda: Mulemba, 2013.

OLIVER, R. A Experiência africana. Rio de Janeiro: Jorge Zahar, 1994.

PEREIRA, A. M. África para abandonar estereótipos e distorções. Belo Horizonte: Nandyala, 2010.

PHIPPS, W. E. Phipps Amazing Grece in John Newton: slave ship captein, hymn writer, and abolitionist. Grorgia: Mercer University Press, 2001.

SAGE, H.W. Briton and boer: both sides of South African question. New York and London: Harper \& brothers, 1900.New York and London, Harper \& brothers

SAID, Edward W. Orientalismo: o Oriente como invenção do Ocidente. Trad. Tomás RosaBueno. São Paulo: Companhia das Letras, 2001. 
SILVA, Alberto da Costa. A enxada e a lança. A África antes dos portugueses. Rio de Janeiro: Nova Fronteira, 2006.

SILVA, Alberto da Costa A manilha e o libambo: a África e a escravidão de 1500 a 1700. Rio de Janeiro: Nova Fronteir; Fundação Biblioteca Nacional, 2002.

SOUTH AFRICA. Act 1909 de Union South Africa.

SOUTH AFRICA. Convention for the Settlement of the Transvaal Territory, 1881.

THOMPSON, E. P. Senhores e Caçadores: a origem da lei negra. Rio de Janeiro: Paz e Terra, 1987.

THOMPSON, E. P. A História Vista de Baixo: as peculiaridades dos ingleses e outros artigos. São Paulo: UNICAMP, 2001. p.185-201

THEAL, G. M. Boers and Bantu: history of the wanderings and wars of the emigrant farmers from their leaving the Cape Colony to the overthrow of Digan.

VILHENA, Maria da Conceição. Gungunhana no seu reino. Lisboa: Colibri, 1996.

WAMBA-DIA-WAMBA, E. L'autodétermination des peuples et le statut de l'histoire. Politique africaine. Paris, n.46, Jun. 1992. Disponível em: <http://www.politiqueafricaine.com/numeros/046_SOM.HTM> Acesso: 20 set 2011. 